\title{
In-vitro influence of mycophenolate mofetil (MMF) and Ciclosporin A (CsA) on cytokine induced killer (CIK) cell immunotherapy
}

Melanie Bremm ${ }^{1 * \dagger}$, Sabine Huenecke ${ }^{1 \dagger}$, Olga Zimmermann', Verena Pfirrmann ${ }^{1}$, Andrea Quaiser ${ }^{1}$, Halvard Bonig ${ }^{2,3}$, Jan Soerensen ${ }^{1}$, Thomas Klingebiel ${ }^{1}$, Eva Rettinger ${ }^{1}$, Peter Bader ${ }^{1}$ and Claudia Cappel ${ }^{1}$

\begin{abstract}
Background: Cytokine-induced-killer (CIK) cells are a promising immunotherapeutic approach for impending relapse following hematopoietic stem cell transplantation (HSCT). However, there is a high risk for treatment failure associated with severe graft versus host disease (GvHD) necessitating pharmaceutical intervention post-transplant. Whether immunosuppression with mycophenolate mofetil (MMF) or Ciclosporin A (CsA) influences the cytotoxic effect of CIK cell immunotherapy is still an open issue.

Methods: CIK cells were generated from PBMC as previously described followed by co-incubation with mycophenolic acid (MPA) or CsA. Proliferation, cytotoxicity and receptor expression were investigated following short- (24 h), intermediate- (3 days) and long-term (7 days) MPA incubation with the intention to simulate the in vivo situation when CIK cells were given to a patient with relevant MPA/CsA plasma levels.

Results: Short-term MPA treatment led to unchanged proliferation capacity and barely had any effect on viability and cytotoxic capability in vitro. The composition of CIK cells with respect to T-, NK-like T- and NK cells remained stable. Intermediate MPA treatment lacked effects on NKG2D, FasL and TRAIL receptor expression, while an influence on proliferation and viability was detectable. Furthermore, long-term treatment significantly impaired proliferation, restricted viability and drastically reduced migration-relevant receptors accompanied by an alteration in the CD4/CD8 ratio. $\mathrm{CD}^{+}{ }^{+} \mathrm{CD} 56^{+}$cells upregulated receptors relevant for CIK cell killing and migration, whereas $\mathrm{T}$ cells showed the most interference through significant reductions in receptor expression. Interestingly, CsA treatment had no significant influence on CIK cell viability and the cytotoxic potential against K562.
\end{abstract}

Conclusions: Our data indicate that if immunosuppressant therapy is indispensable, efficacy of CIK cells is maintained at least short-term, although more frequent dosing might be necessary.

Keywords: MMF, MPA, CIK cells, Immunosuppressive therapy, Immunotherapy, Allogeneic stem cell transplantation

\section{Background}

The transplantation of allogeneic hematopoietic stem cells (HSCT) is an established therapy option for the
*Correspondence: melanie.bremm@kgu.de

${ }^{\dagger}$ Melanie Bremm and Sabine Huenecke contributed equally to this work

${ }^{1}$ Clinic for Pediatric and Adolescent Medicine, University Hospital,

Theodor-Stern-Kai 7, 60596 Frankfurt/Main, Germany

Full list of author information is available at the end of the article treatment of relapsed leukemia and other hematological disorders [1,2].

For prevention and treatment of severe GvHD following HSCT, the immunosuppressive drug mycophenolate mofetil (MMF; Cellcept) and Ciclosporin A (CsA) may be administered [3]. MMF is a prodrug which is systemically metabolized to the active metabolite mycophenolic acid (MPA). MPA non-competitively inhibits inosine monophosphate dehydrogenase (IMPDH) which plays 
an important role in the de novo nucleotide synthesis. Thereby, MPA effectively inhibits the cell proliferation depending on de novo nucleotide synthesis [4-7]. CsA is a calcineurin inhibitor, which suppresses the activation of IL-2 transcription leading to a reduced immune response especially of T cells [8]. Patients with aGVHD >grade I and/or immunosuppression are not eligible for CIK cell therapy. Anyhow, relevant MPA plasma levels might still be present at the time of CIK cell treatment due to intraand inter-patient variability. In addition, CIK cells may cause GvHD necessitating pharmaceutical intervention, which among others may include the administration of MMF. We previously investigated the influence of MMF on NK cells within the scope of a clinical phase I/II study where patients received IL-2 stimulated NK cell immunotherapy to target high-risk leukemia or tumors. In this evaluation we observed that short-term $(24 \mathrm{~h}) \mathrm{MPA}$ incubation had no or marginal effects on the phenotype and only moderately reduced cytotoxic capability of IL2stimulated NK cells in contrast to unstimulated NK cells [9].

In an ongoing study we currently investigate the immunotherapy with cytokine induced killer (CIK) cells derived from peripheral blood mononuclear cells (PBMC) of the stem cell donor via stimulation with interferon (IFN)- $\gamma$, OKT-3, IL-2 and IL-15 over a period of 10-12 days [10-13]. CIK cells are a heterogeneous population primarily consisting of a minor contribution of $\mathrm{CD}^{-}{ }^{-} \mathrm{CD} 56^{+} \mathrm{NK}$ cells and a majority of $\mathrm{CD}^{+} \mathrm{CD} 56^{-}$ $\mathrm{T}$ cells and $\mathrm{CD}^{+}{ }^{+} \mathrm{CD} 56^{+}$NK-like $\mathrm{T}$ cells $[14,15]$. The cytotoxic activity of CIK cells against several tumor cell lines including leukemia, lymphoma and solid tumors was shown [16-19]. Among CIK cells, $\mathrm{CD}^{+}{ }^{+} \mathrm{CD} 56^{+} \mathrm{NK}-$ like $\mathrm{T}$ cells, which are derived from $\mathrm{CD} 3{ }^{+} \mathrm{CD} 56^{-} \mathrm{T}$ cells acquiring the CD56 molecule during expansion, showed the strongest proliferation and cytotoxic potential $[14,20,21]$. In first clinical applications we and others showed the safety and feasibility of CIK cell immunotherapy, including their relatively low propensity for causing GvHD even in only partially MHC-matched recipients $[14,22,23]$. By now, IL-15 activated CIK cells have been licensed as an advanced medicinal product for patients with high-risk leukemia and myelodysplastic syndrome (ATMP $₫ 4 \mathrm{~b}$ Abs. 3 AMG, license number: PEI.A.11630.01.1) [24]. Whether immunosuppressive therapy influences the survival and cytotoxic effect of CIK cell immunotherapy remains an open issue. Therefore, we investigated the in vitro effect of short, intermediate and long-term MPA incubation in therapeutically relevant concentrations on CIK cells which were manufactured over a period of 10-12 days according to our study protocol.

\section{Methods}

\section{CIK cell generation and cultivation}

CIK cells were generated from underweight banked blood of healthy donors (IRB approval 329/10) by standard ficoll separation (Biochrom AG, Berlin Germany). PBMC were adjusted to $3 \times 10^{6}$ cells $/ \mathrm{ml}$ and cultured in X-VIVO 10 media (Lonza, Verviers, Belgium) supplemented with $10 \%$ fresh frozen plasma (German Red Cross Blood Donor Service, Frankfurt, Germany) in cell culture flasks (Greiner, Nürtingen, Germany) at $37^{\circ} \mathrm{C}$ and $5 \% \mathrm{CO}_{2}$. At day 0 of CIK generation $1000 \mathrm{U} /$ ml IFN- $\gamma$ (Imukin ${ }^{\circledR}$, Boeringer Ingelheim Pharma, Germany) were added, followed by $100 \mathrm{ng} / \mathrm{ml}$ anti-CD3 mAB (OKT3, MACS GMP CD3 pure, Miltenyi Biotec, Bergisch Gladbach, Germany) and $500 \mathrm{U} / \mathrm{ml} \mathrm{IL-2}$ (Proleukin ${ }^{\circledR}$ S, Novartis Pharma, Nuremberg, Germany) $24 \mathrm{~h}$ later (day 1 ). On days 4 and 8 of culture, cell density was adjusted to $1 \times 10^{6}$ cells $/ \mathrm{ml}$ and cells were restimulated with 50 ng/ml IL-15 (PeproTech, Rocky Hill, USA) until they were harvested on day 10 . CIK cells were split; control flasks were further supplemented only with $50 \mathrm{ng} / \mathrm{ml}$ IL-15 every 3 days, test flasks were additionally spiked with a therapeutically relevant MPA concentration of $10 \mu \mathrm{M}$ (Sigma-Aldrich, Taufkirchen, Germany) or of $5 \mu \mathrm{g} / \mathrm{ml}$ Ciclosporin A (CsA, Sandimmun ${ }^{\circledR}$, Novartis Pharma GmbH, Nuremberg) after harvesting. The long term series received a further MPA/CsA treatment 3 days following harvesting.

\section{Preparation for ex vivo investigations}

For the experiments regarding cytotoxicity, surface receptor expression and cytokine/chemokine secretion, bench scale CIK cells of healthy donors were used ( $n=6$, independent experiments). Co-incubation experiments with/without MPA/CsA started after 10 days of cultivation. Proliferation, cytokine secretion and receptor expression was investigated following short- $(24 \mathrm{~h})$, intermediate- (3 days) and long-term (7 days) MPA treatment, whereas cytotoxicity was investigated following shortand intermediate-term MPA incubation, only (Fig. 1).

\section{Flow cytometric analyses}

Flow cytometric analyses of CIK cells were performed on a Navios ${ }^{\mathrm{TM}} 10$-color and a FC500 5-color flow cytometer (both Beckman Coulter, Krefeld, Germany). For cell staining monoclonal antibodies conjugated with fluorescein-isothiocyanate (FITC), phycoerythrin (PE), phycoerythrin-Texas $\operatorname{Red}^{\circledR}$ (ECD), phycoerythrin-cyanine-5 and 5.5 (PC-5 and PC-5.5), phycoerythrin-cyanine-7 (PC-7), allophycocyanin (APC), APC-Alexa Fluor 700 (APC-A700), APC-Alexa Fluor 750 (APC-A750), Pacific Blue $^{\mathrm{TM}}(\mathrm{PB})$, Krome Orange (KO) were used against 


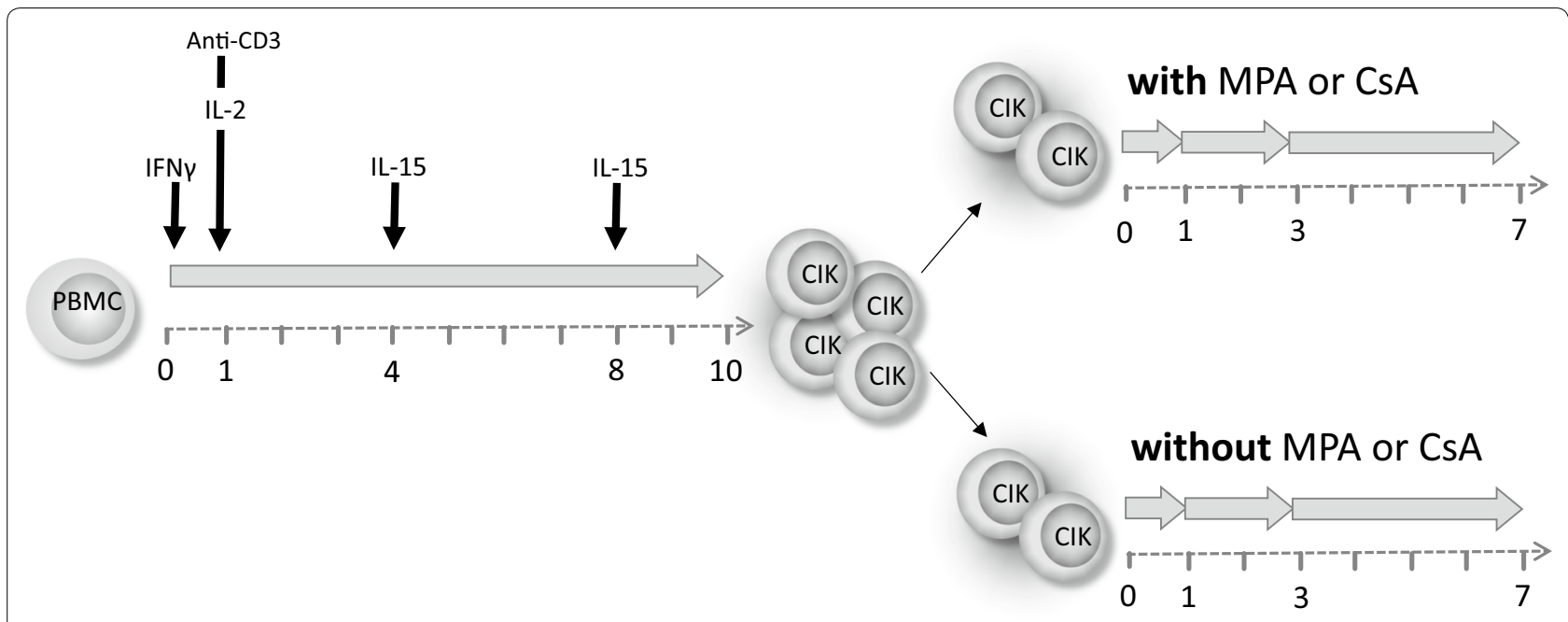

Fig. 1 Experimental schedule of short-, intermediate- and long-term MPA/CsA incubation. CIK cells were generated by stimulation with interferon (IFN)- $\gamma$, OKT3, IL-2 and IL-15 over a period of 10 days. Subsequently, cells were split and either supplemented with $50 \mathrm{ng} / \mathrm{ml}$ IL-15 every 3 days (control) or additionally treated with $10 \mu \mathrm{M}$ MPA or $5 \mu \mathrm{g} / \mathrm{ml}$ CsA. Proliferation, cytokine secretion and receptor expression were investigated following short- (24 h), intermediate- (3 days) and long-term (7 days) MPA treatment

following antigens (clones): FITC: TCR $\delta$ (IMMU510), CD62L (DREG56), CD226/DNAM-1 (DX11), CD11a/ LFA-1 (HI11) $)^{2}$, PE: TCR $\alpha \beta(\mathrm{BW} 242 / 412)^{1}$, CD314/ NKG2D (ON72)/(149810 $)^{4}$, CD173/CD95L/FAS-Ligand $(\mathrm{NOK}-1)^{2}, \mathrm{CD} 183 / \mathrm{CXCR} 3(2 \mathrm{D} 7)^{2}, \mathrm{CD} 195 / \mathrm{CCR} 5(1 \mathrm{C6})^{2}$, CD262/DR5/TRAIL (DJR2-4)3; ECD: CD19 (J3-119), CD45RO (UCHL1); PC-5.5: CD45 (J.33), CD45RO (UCHL1); PC-7: CD56 (N901/NKH-1); APC: CD3 (UCHT1), CD4 (13B8.2); APC-A700: CD25 (B1.49.9); APC-A750: CD16 (3GB), CD3 (UCHT1); PB: CD14 (RMO52), CD45RA (2H4); KO: CD45 (J.33), CD8 (B9.11) (all mouse IgG1, other than ${ }^{\#}$ IgG2a, "IgG2b, all antibodies Beckman Coulter, except ${ }^{1}$ Miltenyi Biotec, ${ }^{2} \mathrm{BD}$ Biosciences; ${ }^{3}$ Biolegend, ${ }^{4} R \& D$ Systems). For the assessment of cell viability 7-AAD was used. Absolute counts were calculated via single-platform using Flow-Count ${ }^{\mathrm{TM}}$ fluorospheres (Beckman Coulter, Krefeld, Germany). All data were analyzed using CXP system II (Vs 2.2), Navios (Vs. 1.2) or Kaluza (Vs. 1.2) software (Beckman Coulter, Krefeld, Germany).

\section{Cytotoxicity assay}

CIK cell cytotoxicity was tested against THP-1, K562 and MOLT-4 using the non-radioactive europium release cytotoxicity assay as described previously [16, $20]$. To avoid the known discharge of the labeling reagent BATDA, K562 were previously incubated with Probenecid (Sigma-Aldrich Chemie GmbH, Steinheim, Germany). Target cells and CIK effector cells were cocultured in triplicates at effector to target (E:T) ratios 40:1, 20:1, 10:1 and 5:1 on U-bottomed 96-well culture

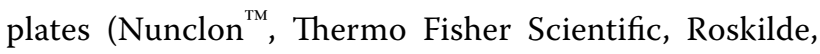
Denmark). After $3 \mathrm{~h}$ co-incubation at $37^{\circ} \mathrm{C}, 20 \mu \mathrm{l}$ supernatant was collected from each well and incubated for $15 \mathrm{~min}$ (shaking, $250 \mathrm{rpm}$ ) with $200 \mu \mathrm{l}$ Europium solution (PerkinElmer, Boston, USA). The fluorescence signal, correlating with the amount of destroyed cells, was then measured by a multilabel plate reader (VIC$\mathrm{TOR}^{3^{\mathrm{TM}}} 1420$ multilabel counter, PerkinElmer, Boston USA). Target cells without effector cells were used as negative control. Maximum release (positive control) was obtained by target cell incubation with $16 \%$ Triton $^{\mathrm{TM}}$ X-100 solution (Sigma-Aldrich Chemie, Steinheim, Germany). Percentage of specific cytotoxicity was defined as the loss of target cells in relation to the mono-cultured control.

\section{Cytokine/chemokine analysis}

Supernatants of expanded CIK cells after 10 days of cultivation and then following $24 \mathrm{~h}, 3$ and 7 days MPA incubation $(10 \mu \mathrm{M})$ with respective controls were collected and assayed using BioLegend LEGENDplex ${ }^{\mathrm{TM}}$ (BioLegend, San Diego, USA). Data acquisition was performed on a Navios Flow Cytometer and analyzed with the LEGENDplex ${ }^{\mathrm{TM}}$ Data Analysis Software (BioLegend, San Diego, USA). The cell density was adjusted to $3 \times 10^{6} / \mathrm{ml}$. The human inflammation 13-plex panel was designed for quantification of the cytokines/chemokines IL- $1 \beta$, IFN- $\alpha$, IFN- $\gamma$, TNF- $\alpha$, MCP-1/CCL2, IL-6, IL-8, IL-10, IL-12p70, IL-17A, IL-18, IL-23 and IL-33. The minimum detectable concentration for the cytokines ranged from 0.6 to $2.1 \mathrm{pg} / \mathrm{ml}$. 


\section{Statistical analysis}

Statistical analysis was performed using GraphPad Prism 6 for Windows (GraphPad Software, San Diego, USA). Data were compared by paired, non-parametric Friedmann test and differences were considered as significant for $\mathrm{p}<0.05\left(^{*}\right), \mathrm{p}<0.01\left(^{* * *}\right)$ and $\mathrm{p}<0.001{ }^{(* * *)}$.

\section{Results}

\section{Influence of MPA/CsA treatment on CIK cell expansion} and viability

CIK cells that were cultivated in the presence of MPA for at least 3 days showed significantly impaired proliferation capacity compared to CIK cells cultivated without MPA over an equal period of time ( $<<0.01$; Fig. $2 \mathrm{a})$. These differences were also demonstrated for all three CIK cell subgroups following intermediate- and for T- and NK cells following long-term MPA treatment $(p<0.05)$. Contrary, no effect of CsA treatment on CIK cell proliferation was observed (Additional file 1: Figure S1A). Interestingly, short-term MPA treatment had no or only marginal effect on CIK cell viability. In contrast, intermediate and long-term MPA treatment reduced CIK cell viability by more than $30 \%$ whereas CsA treatment had no significant influence on CIK cell viability ( $\mathrm{p}<0.01$; Fig. $2 \mathrm{~b})$.

\section{Cytotoxic capacity of CIK cells following MPA/CsA treatment}

Cytotoxicity of CIK cells with and without MPA treatment was investigated against the ALL cell line MOLT-4 and the AML cell lines K562 and THP-1 whereas CsA treatment was investigated against the cell lines $\mathrm{K} 562$ and MOLT-4 (Fig. 3). The cytotoxic effect of MPA treated CIK cells against K562 cells was influenced by MPA exposure, though only in the 40:1 ratio a significant reduction of the killing capacity was obtained ( $\mathrm{p}<0.05$, Fig. 3a). In contrast, no differences in the lytic activity of CsA incubated and wildtype CIK cells were observed against K562 (Fig. 3b). Regarding MOLT-4 killing, short-term MPA treatment did not affect target cell lysis compared to untreated control CIK cells (Fig. 3c). However we observed a reduced lysis of MOLT-4 cells by CIK cells treated with MPA for 3 days (intermediate term) in the $\mathrm{E}: \mathrm{T}$ ratios 10:1, 20:1 and 40:1 ( $\mathrm{p}<0.05)$. CsA-treated and wildtype CIK cells showed comparable results in MOLT-4 killing (data not shown). Interestingly, no difference in the lysis of THP-1 target cells of CIK cells with and without MPA incubation were determined (Fig. 3d). Long-term MPA treatment resulted in strong reduction of absolute CIK cell number. Therefore, cytotoxicity testing could not be investigated.

\section{Changes in receptor expression and cytokine secretion as consequence of MPA treatment}

Although absolute numbers of $\mathrm{T}$ cells declined, we observed an alteration in the CD4/CD8 ratio following MPA treatment of CIK cells. Interestingly, the percentage of $\mathrm{CD}^{+}$cells decreased, while the percentage of $\mathrm{CD}^{+}$cells increased (Fig. 4a). Comparing the proportion of $\mathrm{CD}^{+}$cells following long-term and without MPA treatment revealed a significant decrease in $\mathrm{CD}^{+}$cells ( $\mathrm{p}<0.05)$. In accordance, intermediate and long-term MPA incubation were associated with a statistically significant higher percentage of $\mathrm{CD}^{+}$cells $(\mathrm{p}<0.05$ and $\mathrm{p}<0.01)$.

The characterization of NKG2D receptor on $\mathrm{CD}_{4}^{+}$and $\mathrm{CD}^{+}$cells showed stable expression upon short- and intermediate-term MPA treatment. Only following longterm MPA incubation, downregulation of NKG2D was observed ( $p<0.05$, Fig. $4 b$ ). Further analysis also revealed stable expression of NKG2D on CIK cell subpopulations (T, NK and NK-like T cells) during short- and intermediate-term MPA incubation, whereas reduced NKG2D receptor expression was observed following long-term MPA exposure ( $\mathrm{T}$ and NK cells: $\mathrm{p}<0.05$; NK-like T cells: $\mathrm{p}<0.01$, Fig. 4c).

Regarding CD25, we observed loss of expression when CIK cells were cultivated for longer than the usual culture period of 10 days. However, this reduction in CD25 expression was enhanced following MPA incubation, showing the most pronounced differences for NK-like $\mathrm{T}$ cells after intermediate- and long-term MPA treatment ( $\mathrm{p}<0.01$ ) (Fig. 4d). Interestingly, we also observed a reduction in CD25 expression implicated by CsA treatment. $\mathrm{T}$ and NK-like $\mathrm{T}$ cells showed a significant reduction of CD25 expression following three $(\mathrm{p}<0.01)$ and 7 days $(\mathrm{p}<0.05)$ of CsA treatment whereas no significant alteration of CD25 expression on NK cells was observed (Additional file 1: Figure S1B). Furthermore, no changes in NKG2D expression in CsA treated CIK cells were examined (data not shown).

FasL, TRAIL and DNAM, which are mainly involved in target cell killing, were influenced by MPA to a minor extent. Following long-term MPA treatment we determined a decrease in FasL and TRAIL expression on T cells and an increase of DNAM expression on NK-like T cells ( $\mathrm{p}<0.05$, Fig. 5). In contrast, CD11a, CXCR3 and CCR5, which are primarily involved in CIK cell migration, were more susceptible to MPA exposure. Interestingly, the percentage of $\mathrm{T}$ cells expressing CD11a was reduced, but increased on NK-like $\mathrm{T}$ and NK cells following intermediate- and long-term treatment $(\mathrm{p}<0.05$ and $\mathrm{p}<0.01$ ). Furthermore, T cells showed reduced CXCR3 expression following long-term, whereas NK-like T cells 
a

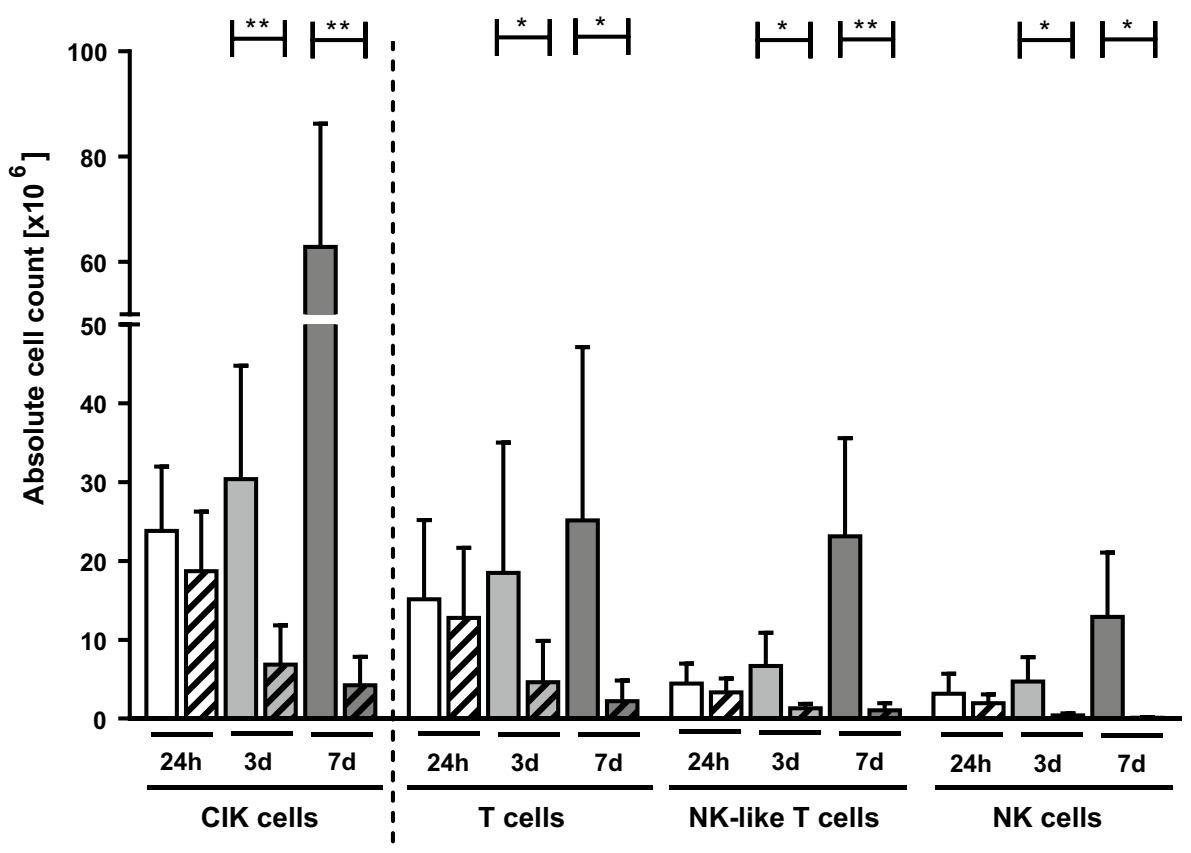

b

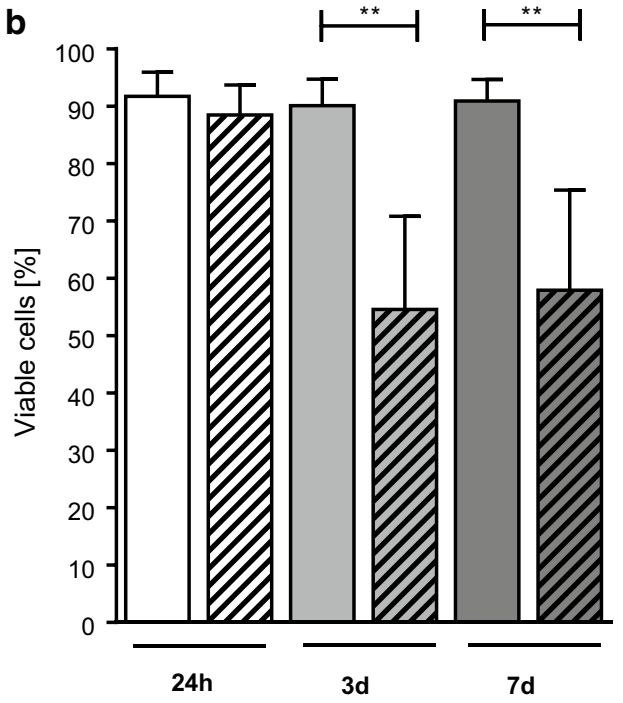

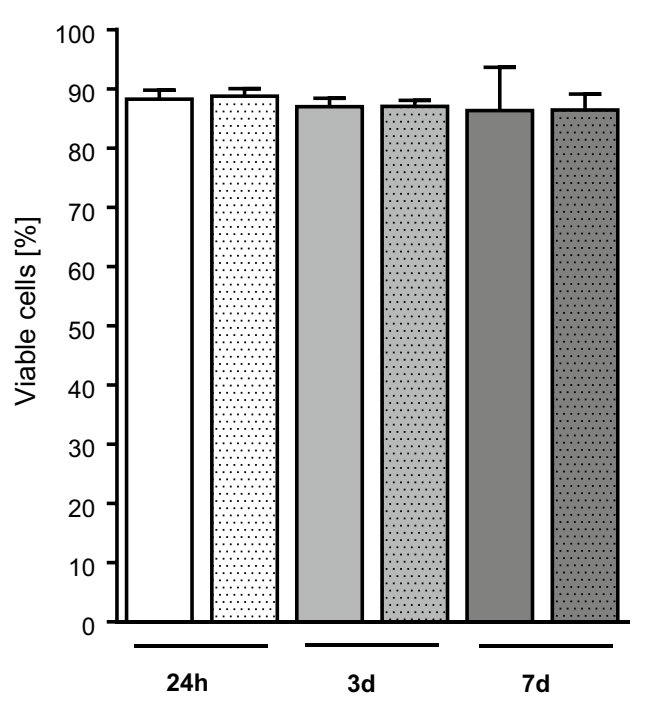

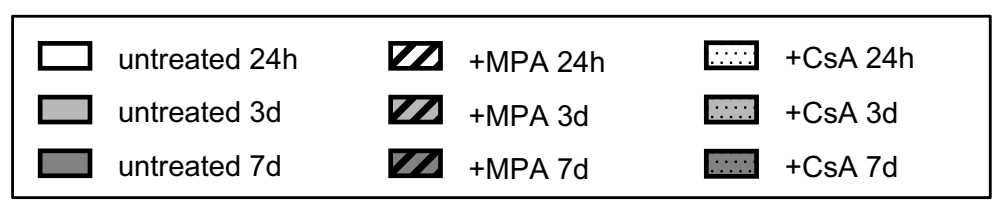

Fig. 2 Ex vivo CIK cell expansion upon MPA- and viability with and without MPA/CsA treatment. a Proliferation capacity of CIK cells in the presence and absence of MPA for the indicated time-points. Intermediate- (3 days) and long-term (7 days) MPA treatment resulted in an impaired proliferation capacity of CIK cells $(p<0.01)$, whereas short-term ( 24 h) MPA exposure had only marginal effect on CIK cell expansion. The most prominent reduction in expansion was seen for NK-like T cells following long-term MPA exposure $(p<0.01)$. b Short-term MPA incubation had no or only marginal effect on CIK cell viability. In contrast, intermediate- and long-term MPA treatment resulted in a significantly reduced CIK cell viability $(p<0.01$; $n=6$ independent experiments). CsA treatment had no effect on CIK cell viability ( $n=4$ independent experiments) 


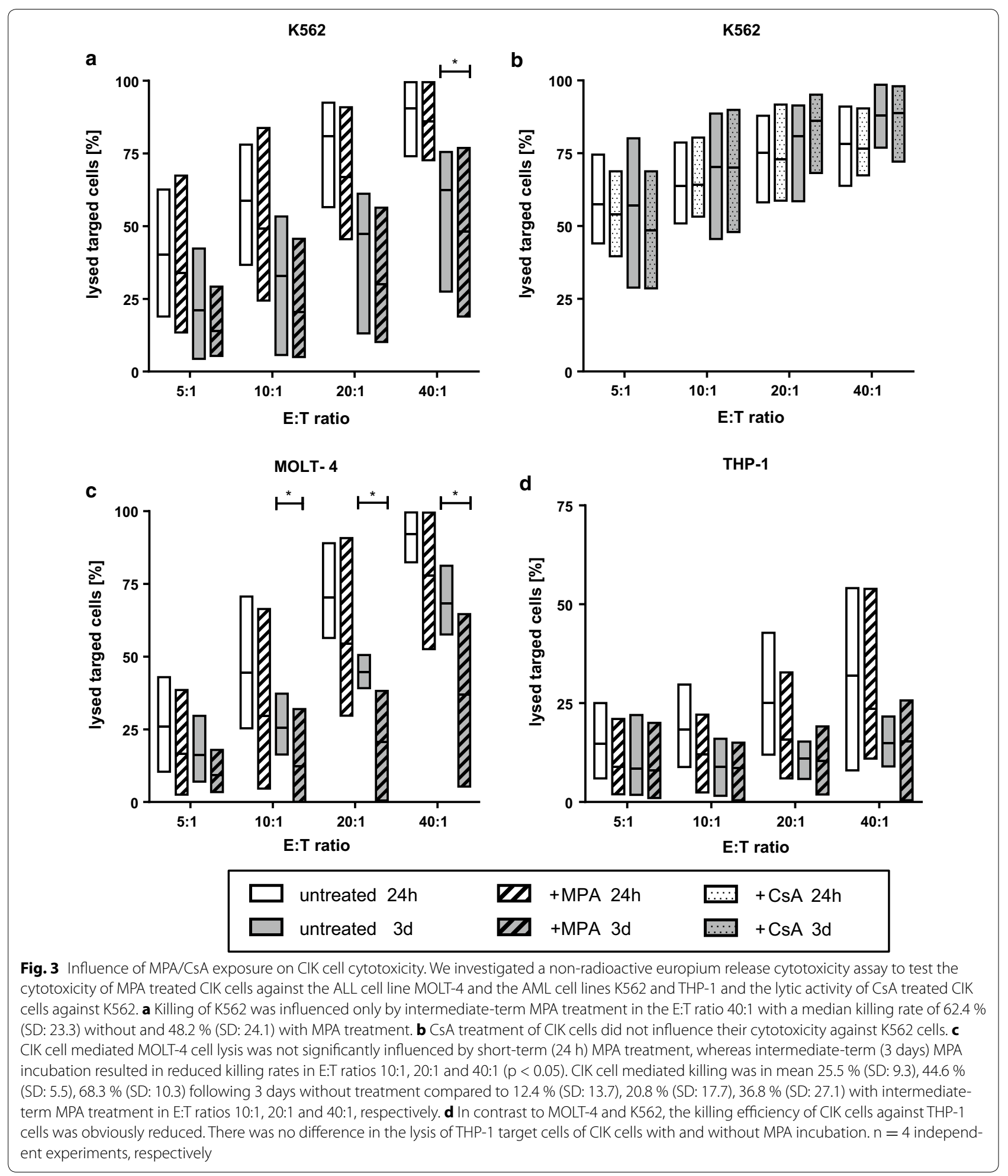

up-regulated CCR5 upon intermediate- and long-term treatment with MPA $(\mathrm{p}<0.05)$.

We also analyzed a panel of cytokines, i.e. IL-8, IFN- $\gamma$, MCP-1/CCL2, IL-6, IL-1 $\beta$ and TNF $\alpha$, following short-, intermediate- and long-term MPA exposure or control incubation. Similar to CD25 expression, cytokine release was attenuated by extended cultivation. In other words, impaired functionality in terms of cytokine release was 

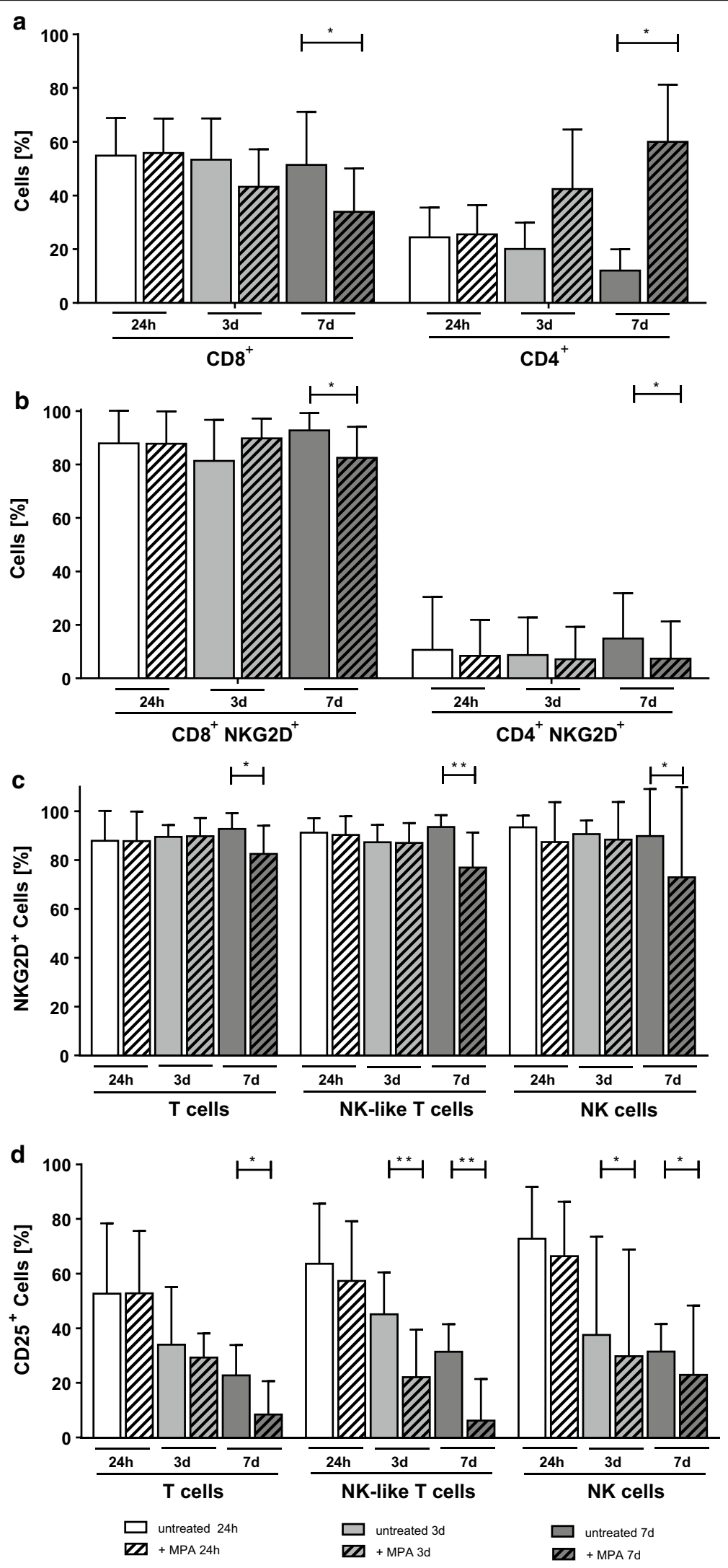
(See figure on previous page.)

Fig. 4 Changes in CIK cell composition induced by MPA treatment. The influence of MPA treatment on receptor expression was analyzed for CD4, CD8, NKG2D and CD25. a The percentage of CD8 ${ }^{+}$cells decreased, whereas the proportion of CD4 $4^{+}$cells increased. $\mathbf{b}$, c NKG2D was steadily expressed during short- ( $24 \mathrm{~h}$ ) and intermediate-term (3 days) MPA treatment, only showing a reduction after long-term (7 days) MPA exposure. d CD25 expression clearly declined on T cells following long-term MPA exposure $(p<0.05)$ and on NK cells following intermediate- and long-term MPA treatment $(p<0.05)$. The most significant reduction in CD25 expression was shown for NK-like T cells after intermediate- and long-term MPA exposure. $n=6$ independent experiments

not primarily influenced by MPA, but rather through the prolonged activation period. The only cytokine significantly reduced after long-term MPA compared to control was TNF $\alpha$ (Additional file 2: Figure S2).

\section{Discussion}

Immunotherapeutic strategies are of increasing interest in the therapy of emerging minimal residual disease or incomplete donor chimerism following HSCT. We and others have previously shown that IL-15 stimulated CIK cells are a promising immunotherapeutic approach for the treatment of patients with impending relapse following allogeneic SCT for acute leukemia or myelodysplastic syndrome $[13,19,22,25,26]$.

CIK cells consist of a heterogeneous population of $\mathrm{CD}^{+}{ }^{+} \mathrm{T}$ cells, $\mathrm{CD}^{+}{ }^{+} \mathrm{CD} 56^{+}$NK-like $\mathrm{T}$ cells and a minor part of $\mathrm{CD}^{-}{ }^{-} \mathrm{CD} 56^{+}$NK cells [14]. Thereby, CIK cells are able to kill tumor cells via diverse TCR specificities and in a non-MHC-restricted manner [27]. Different studies indicated an anti-tumor effect of CIK cells against various tumor cells mediated by the receptors or ligands NKG2D, TRAIL, DNAM and FasL [16, 28, 29]. In first clinical applications, CIK cell infusions were well tolerated and showed low incidence of GvHD even in the haplo-identical setting, which was postulated to be mainly due to less trafficking of CIK cells to GvHD sites [30], and due to the lack of corresponding ligands or receptors on normal tissues and hematopoietic progenitors.

Beside antileukemic efficacy, CIK cell treatment may be associated with increased risk for developing severe GvHD, especially when being applied in the haploidentical setting and in the early post-transplant period requiring immunosuppressive treatment. Furthermore, even if immunosuppression like MMF is stopped in patients at risk for relapse after HSCT, relevant MPA plasma levels might be present due to intra- and inter-patient variability [31]. Therefore, the influence of immunosuppressive treatment, on the efficacy of cellular interventions needs to be further investigated. Hence, we analyzed the phenotype, survival and cytotoxic capacity of CIK cells during short-, intermediate- and long-term presence of MMF in vitro.

Within this study, we observed that CIK cell cytotoxicity was maintained during short-term MPA exposure, while intermediate- and long-term MPA treatment attenuated proliferation capacity, viability and cytotoxicity. Comparable results were obtained by Brehm et al. [9] for NK cells within the scope of a clinical phase I/II study in short- and long-term MPA treatment. In this study, NK cells were co-incubated with MPA just at the beginning of cytokine activation. In our new approach, we first generated the immunotherapeutic cells and then exposed them to MPA. Eissens et al. [32] and Ohata et al. [33] also described that MPA clearly impeded the outgrowth and the cytotoxic effect of NK cells treated with MPA. Unfortunately, a short-term MPA treatment was not investigated in these two studies. These results are contradicting Shapira et al. [34] who suggested that MMF does not impair GvL-effect or reduce LAK cell activity in mice. However, this might be explained by differing study protocols. Shapira et al. treated mice with MMF for a period of 8 days and afterwards generated autologous LAK cells without further addition of MMF. In contrast, we generated CIK cells according to our study protocol for 10 days and started MPA treatment after harvesting with the intention to simulate in vitro the situation when CIK cells were given to a patient who has therapeutic MPA plasma levels.

Most importantly, none or at most a marginal effect on CIK cell proliferation was seen following short-term MPA incubation. Therefore, our findings are promising, that in case of indispensable immunosuppression post

\footnotetext{
(See figure on next page.)

Fig. 5 Influence of MPA exposure on receptors involved in CIK cell mediated killing and cell migration. FasL, TRAIL, DNAM, CD11a, CXCR3 and CCR5 were analyzed following short- ( $24 \mathrm{~h}$ ), intermediate- ( 3 days) and long-term (7 days) MPA treatment and all receptors were compared to their individual controls (only $24 \mathrm{~h}$ control is displayed). a-c Analyzing receptors involved in CIK cell mediated killing, we observed a stable expression of FasL, TRAIL and DNAM upon short- and intermediate-term MPA treatment. A reduced expression of FasL and TRAlL on T cells and an increased expression of DNAM following long-term MPA exposure was determined $(p<0.05)$. $\mathbf{d}-\mathbf{f}$ With regard to CIK cell migration, no alteration in the expression of CD11a, CXCR3 and CCR5 upon short-term MPA exposure was observed. CD11 a was downregulated on T cells and upregulated on NK-like T and NK cells following intermediate- and long-term MPA treatment $(p<0.05$ and $p<0.01)$. CXCR3 was downregulated on T cells upon long-term MPA incubation $(p<0.05)$, whereas CCR5 was expressed to a higher extend on NK-like T cells. $n=5$ independent experiments
} 


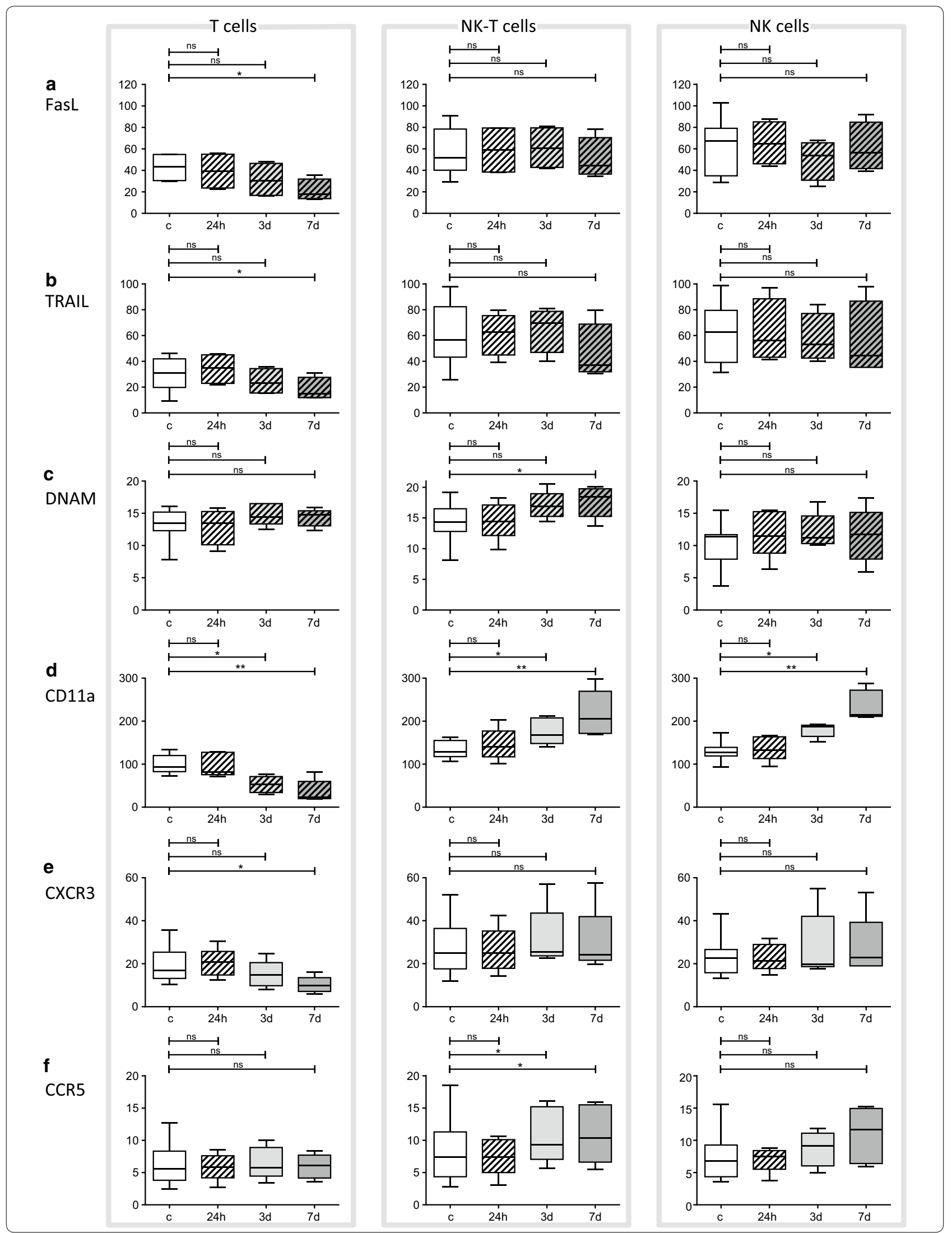


HSCT, the therapy with IL-15 stimulated CIK cells will have at least short-term efficacy. We observed no significant differences of killing relevant receptor expressions of the NKG2D, TRAIL, DNAM and FasL receptors upon short- and intermediate-term MPA exposure. However, we revealed that $\mathrm{T}$ cells and NK-like $\mathrm{T}$ cells reacted differently upon MPA exposure. $\mathrm{CD}^{+}{ }^{+} \mathrm{CD} 56^{+}$NK-like $\mathrm{T}$ cells upregulated receptors relevant for $\mathrm{CIK}$ cell killing and migration, whereas $\mathrm{CD}^{+} \mathrm{T}$ cells downregulated these receptors. CsA treatment resulted in a non-significant reduction of proliferation and cytotoxicity, only. These results are comparable to Mehta et al. [35] describing that CsA inhibited anti-CD3-mediated degranulation, but did not affect cytotoxicity of CIK cells against tumor targets. Regarding cytokine/chemokine secretion, we observed no significant differences between CIK cells with and without MPA treatment expect for a significant reduction in TNF $\alpha$ secretion. These results are in accordance with Liu et al. [36] who published promising results combining CIK cell therapy with CsA treatment also describing the secretion of various cytokines including IL-2 and IL-8. In contrast, Brehm et al. [9] and Nagy et al. [37] reported a significant reduction in the secretion of IFN $\gamma$, IL- 6 and other cytokines by NK cells upon MPA treatment, but here immune cells were co-incubated with MPA already during cultivation time.

Following infusion, CIK cells are described to accumulate and persist in tumor sites, resulting in tumor eradication [30]. Wang et al. [38] analyzed CIK cell homing of ${ }^{18}$ F-FDG labeled CIK cells in leukemia patients by PET/ $\mathrm{CT}$ tracking. They figured out, that $1 \mathrm{~h}$ following CIK cell infusion, the majority of CIK cells accumulated in the lungs, followed by a migration into brain, heart, liver and spleen at the time points 4 and $8 \mathrm{~h}$ post CIK cell therapy. Furthermore, tendencies of CIK cell homing into the bone marrow were shown. In the study described herein, we observed that short-term MPA incubation had no pronounced effect on proliferation, viability, cytotoxicity and CIK cell composition. Linking this information to the homing parameters analyzed by Wang et al., we might speculate that during a window of $24 \mathrm{~h}$ where hardly any influence of MPA on the CIK cells was seen, CIK cells might migrate to tumor sites and achieve a cytotoxic effect.

\section{Conclusions}

In conclusion, already generated IL-15 CIK cells that were co-incubated with MPA for at least 3 days showed significantly impaired proliferation capacity, restricted viability, alterations in receptor expression and a reduction in their cytotoxic capability compared to CIK cells that were cultivated without MPA. Interestingly, CsA treatment had no significant influence on CIK cell viability and the cytotoxic potential against K562. However, a short-term MPA incubation had only marginal or reduced effect on CIK cells. The favored strategy is to avoid immunosuppression in patients who received CIK cell immuno-therapy. However, our findings showed, that even in patients with immunosuppression e.g. for treatment of GvHD, CIK cell treatment may have at least short-term efficacy.

\section{Additional files}

Additional file 1: Figure S1. Ex vivo CIK cell expansion and CD25 expression upon CSA treatment. (A) CSA treated CIK cells showed comparable expansion rates compared to wiltype CIK cells. (B) CD25 expression significantly decreased on T and NK-like T cells following 3 and 7 days of CsA incubation (day 3: $p<0.01$ and day 7: $p<0.05$ ).

Additional file 2: Figure S2. Impact of MPA treatment on cytokine secretion. Analyzing the secretion of IL-8, IFNy, MCP-1/CCL2, IL-6, IL-1 $\beta$ and TNFa, we only determined a significant decrease in TNFa secretion upon long-term MPA exposure $(p<0.01) . n=4$ independent results in triplicates. Abbreviations: $c=$ control, + MPA $=$ following MPA treatment.

\section{Abbreviations}

APC: allophycocyanin; APC-A700: APC-Alexa Fluor 700; APC-A750: APC-Alexa Fluor 750; CIK: cytokine-induced killer; CsA: Ciclosporin A; FITC: fluoresceinisothiocyanate; ECD: phycoerythrin-Texas Red ${ }^{\circledR} ; \mathrm{GVL} / \mathrm{T}$ : graft-versus-leukemia/ tumor; DLI: donor lymphocyte infusion; GVHD: graft-versus-host disease; GMP: good manufacturing practice; HSCT: hematopoietic stem cell transplantation; KO: krome orange; MMF: mycophenolate mofetil; MPA: mycophenolic acid; MRD: minimal residual disease; NK: natural killer; PBMC: peripheral blood mononuclear cells; PB: pacific blue ${ }^{\text {TM }} ;$ PC-5: phycoerythrin-cyanine-5; PC-7: phycoerythrin-cyanine-7; PE: phycoerythrin.

\section{Authors' contributions}

Conceived and designed the experiments: MB, SH, CC. Performed the experiments: OZ, AQ. Analyzed the data: MB, SH, AQ. Coordinated the research: $\mathrm{SH}$, CC. Contributed reagents/materials/analysis tools: MB, SH, VP, OZ, AQ. Wrote the paper: MB, SH. Revised the manuscript: HB, ER, CC, VP, JS. Supervised the research: PB, TK. All authors read and approved the final manuscript.

\section{Author details}

${ }^{1}$ Clinic for Pediatric and Adolescent Medicine, University Hospital, Theodor-Stern-Kai 7, 60596 Frankfurt/Main, Germany. ${ }^{2}$ Division for Translational Development of Cellular Therapeutics, Institute for Transfusion Medicine and Immunohematology, Goethe-University Frankfurt/Main, Frankfurt/Main, Germany. ${ }^{3}$ German Red Cross Blood Donor Service Baden-WürttembergHessen, Frankfurt/Main, Germany.

\section{Acknowledgements}

The authors would like to thank Sibille Betz and Stephanie Erben for the excellent technical support.

\section{Competing interests}

The authors declare that they have no competing interests.

Availability of data and materials

All data are available in the manuscript or upon request to the authors.

\section{Ethics approval and consent to participate}

Donor PBMCs were obtained after written informed consent was given, with approval from the Ethical Review Board of the Medical Faculty of the University Hospital Frankfurt (IRB approval 329/10). 


\section{Funding}

This project was supported by "Frankfurter Stiftung für krebskranke Kinder" and "Hilfe für krebskranke Kinder e.V.", as well as "LOEWE Center for Cell and Gene Therapy Frankfurt; funded by: Hessisches Ministerium für Wissenschaft und Kunst (HMWK); funding reference number: III L 5-518/17.004". The funders had no role in study design, data collection and analysis, decision to publish, or preparation of the manuscript.

Received: 30 April 2016 Accepted: 30 August 2016 Published online: 13 September 2016

\section{References}

1. Barrett AJ, Horowitz MM, Pollock BH, Zhang MJ, Bortin MM, Buchanan GR, Camitta BM, Ochs J, Graham-Pole J, Rowlings PA, et al. Bone marrow transplants from HLA-identical siblings as compared with chemotherapy for children with acute lymphoblastic leukemia in a second remission. $\mathrm{N}$ Engl J Med. 1994;331:1253-8.

2. Klingebiel T, Handgretinger R, Lang P, Bader P, Niethammer D. Haploidentical transplantation for acute lymphoblastic leukemia in childhood. Blood Rev. 2004;18:181-92.

3. Windreich RM, Goyal RK, Joshi R, Kenkre TS, Howrie D, Venkataramanan R. A pilot study of continuous infusion of mycophenolate mofetil for prophylaxis of graft-versus-host-disease in pediatric patients. Biol Blood Marrow Transplant. 2016;22(4):682-9.

4. Allison AC, Eugui EM. Mycophenolate mofetil and its mechanisms of action. Immunopharmacology. 2000;47:85-118.

5. Allison AC, Eugui EM. Mechanisms of action of mycophenolate mofetil in preventing acute and chronic allograft rejection. Transplantation. 2005;80:S181-90.

6. Eugui EM, Allison AC. Immunosuppressive activity of mycophenolate mofetil. Ann N Y Acad Sci. 1993;685:309-29.

7. van Gelder T, Hesselink DA. Mycophenolate revisited. Transpl Int. 2015;28:508-15

8. Laupacis A, Keown PA, Ulan RA, McKenzie N, Stiller CR. Cyclosporin A: a powerful immunosuppressant. Can Med Assoc J. 1982;126:1041-6.

9. Brehm C, Huenecke S, Esser R, Kloess S, Quaiser A, Betz S, Zimmermann $\mathrm{O}$, Soerensen J, Passweg JR, Klingebiel T, et al. Interleukin-2-stimulated natural killer cells are less susceptible to mycophenolate mofetil than non-activated NK cells: possible consequences for immunotherapy. Cancer Immunol Immunother. 2014;63:821-33.

10. Rettinger $E$, Bonig $H$, Wehner S, Lucchini G, Willasch A, Jarisch A, Soerensen J, Esser R, Rossig C, Klingebiel T, Bader P. Feasibility of IL-15-activated cytokine-induced killer cell infusions after haploidentical stem cell transplantation. Bone Marrow Transplant. 2013:48:1141-3.

11. Rettinger E, Kreyenberg H, Merker M, Kuci S, Willasch A, Bug G, Ullrich E, Wels WS, Bonig H, Klingebiel T, Bader P. Immunomagnetic selection or irradiation eliminates alloreactive cells but also reduces anti-tumor potential of cytokine-induced killer cells: implications for unmanipulated cytokine-induced killer cell infusion. Cytotherapy. 2014;16:835-44.

12. Rettinger E, Kuci S, Naumann I, Becker P, Kreyenberg H, Anzaghe M, Willasch A, Koehl U, Bug G, Ruthardt M, et al. The cytotoxic potential of interleukin-15-stimulated cytokine-induced killer cells against leukemia cells. Cytotherapy. 2012;14:91-103

13. Rettinger $E$, Meyer $V$, Kreyenberg H, Volk A, Kuci S, Willasch A, Koscielniak E, Fulda S, Wels WS, Boenig H, et al. Cytotoxic capacity of IL-15-stimulated cytokine-induced killer cells against human acute myeloid leukemia and rhabdomyosarcoma in humanized preclinical mouse models. Front Oncol. 2012;2:32.

14. Linn YC, Niam M, Chu S, Choong A, Yong HX, Heng KK, Hwang W, Loh Y, Goh YT, Suck G, et al. The anti-tumour activity of allogeneic cytokineinduced killer cells in patients who relapse after allogeneic transplant for haematological malignancies. Bone Marrow Transplant. 2012;47:957-66.

15. Schmidt-Wolf IG, Lefterova P, Mehta BA, Fernandez LP, Huhn D, Blume KG, Weissman IL, Negrin RS. Phenotypic characterization and identification of effector cells involved in tumor cell recognition of cytokine-induced killer cells. Exp Hematol. 1993;21:1673-9.

16. Kuci S, Rettinger E, Voss B, Weber G, Stais M, Kreyenberg H, Willasch A, Kuci Z, Koscielniak E, Kloss S, et al. Efficient lysis of rhabdomyosarcoma cells by cytokine-induced killer cells: implications for adoptive immunotherapy after allogeneic stem cell transplantation. Haematologica. 2010;95:1579-86.

17. Linn YC, Lau LC, Hui KM. Generation of cytokine-induced killer cells from leukaemic samples with in vitro cytotoxicity against autologous and allogeneic leukaemic blasts. Br J Haematol. 2002;116:78-86.

18. Schmidt-Wolf IG, Negrin RS, Kiem HP, Blume KG, Weissman IL. Use of a SCID mouse/human lymphoma model to evaluate cytokineinduced killer cells with potent antitumor cell activity. J Exp Med. 1991;174:139-49.

19. Schmeel LC, Schmeel FC, Coch C, Schmidt-Wolf IG. Cytokine-induced killer (CIK) cells in cancer immunotherapy: report of the international registry on CIK cells (IRCC). J Cancer Res Clin Oncol. 2015;141:839-49.

20. Cappel C, Huenecke S, Suemmerer A, Erben S, Rettinger E, Pfirrmann $V$, Klingebiel T, Ullrich E, Bader P, Bremm M. Cytotoxic potential of IL15-activated cytokine-induced killer cells against human neuroblastoma cells. Pediatr Blood Cancer. 2016; . doi:10.1002/pbc.26147.

21. Lu PH, Negrin RS. A novel population of expanded human $\mathrm{CD}^{+} \mathrm{CD}_{5} 6^{+}$ cells derived from T cells with potent in vivo antitumor activity in mice with severe combined immunodeficiency. J Immunol. 1994;153:1687-96.

22. Introna M, Borleri G, Conti E, Franceschetti M, Barbui AM, Broady R, Dander E, Gaipa G, D'Amico G, Biagi E, et al. Repeated infusions of donorderived cytokine-induced killer cells in patients relapsing after allogeneic stem cell transplantation: a phase I study. Haematologica. 2007;92:952-9.

23. Laport GG, Sheehan K, Baker J, Armstrong R, Wong RM, Lowsky R, Johnston LJ, Shizuru JA, Miklos D, Arai S, et al. Adoptive immunotherapy with cytokine-induced killer cells for patients with relapsed hematologic malignancies after allogeneic hematopoietic cell transplantation. Biol Blood Marrow Transplant. 2011:17:1679-87.

24. Rettinger E, Huenecke S, Bonig H, Merker M, Jarisch A, Soerensen J, Willasch A, Bug G, Schulz A, Klingebiel T, Bader P. Interleukin-15-activated cytokine-induced killer cells may sustain remission in leukemia patients after allogeneic stem cell transplantation: feasibility, safety and first insights on efficacy. Haematologica. 2016;101:e153-6.

25. Rettinger E, Huenecke S, Bonig H, Merker M, Jarisch A, Soerensen J, Willasch A, Bug G, Schulz A, Klingebiel T, Bader P. IL-15-activated cytokineinduced killer cells may sustain remission in leukemia patients after allogeneic stem cell transplantation: feasibility, safety and first insights on efficacy. Haematologica. 2016;101(4):e153-6.

26. Sangiolo D, Mesiano G, Carnevale-Schianca F, Piacibello W, Aglietta M, Cignetti A. Cytokine induced killer cells as adoptive immunotherapy strategy to augment graft versus tumor after hematopoietic cell transplantation. Expert Opin Biol Ther. 2009;9:831-40.

27. Jiang J, Wu C, Lu B. Cytokine-induced killer cells promote antitumor immunity. J Transl Med. 2013;11:83.

28. Pievani A, Borleri G, Pende D, Moretta L, Rambaldi A, Golay J, Introna M. Dual-functional capability of $\mathrm{CD}^{+}{ }^{+} \mathrm{CD} 56^{+} \mathrm{CIK}$ cells, a T-cell subset that acquires NK function and retains TCR-mediated specific cytotoxicity. Blood. 2011;118:3301-10.

29. Verneris MR, Kornacker M, Mailander V, Negrin RS. Resistance of ex vivo expanded $\mathrm{CD}^{+}{ }^{+} \mathrm{CD}_{56}{ }^{+} \mathrm{T}$ cells to Fas-mediated apoptosis. Cancer Immunol Immunother. 2000;49:335-45.

30. Nishimura R, Baker J, Beilhack A, Zeiser R, Olson JA, Sega El, Karimi M, Negrin RS. In vivo trafficking and survival of cytokine-induced killer cells resulting in minimal GVHD with retention of antitumor activity. Blood. 2008; 112:2563-74.

31. Bhatia M, Militano O, Jin Z, Figurski M, Shaw L, Moore V, Morris E, Tallamy $B$, van deVen C, Ayello J, et al. An age-dependent pharmacokinetic study of intravenous and oral mycophenolate mofetil in combination with tacrolimus for GVHD prophylaxis in pediatric allogeneic stem cell transplantation recipients. Biol Blood Marrow Transplant. 2010;16:333-43.

32. Eissens DN, Van Der Meer A, Van Cranenbroek B, Preijers FW, Joosten I. Rapamycin and MPA, but not CsA, impair human NK cell cytotoxicity due to differential effects on NK cell phenotype. Am J Transplant. 2010;10:1981-90

33. Ohata K, Espinoza JL, Lu X, Kondo Y, Nakao S. Mycophenolic acid inhibits natural killer cell proliferation and cytotoxic function: a possible disadvantage of including mycophenolate mofetil in the graft-versus-host disease prophylaxis regimen. Biol Blood Marrow Transplant. 2011;17:205-13.

34. Shapira MY, Hirshfeld E, Weiss L, Zeira M, Kasir J, Or R, Resnick IB, Slavin S. Mycophenolate mofetil does not suppress the graft-versus-leukemia 
effect or the activity of lymphokine-activated killer (LAK) cells in a murine model. Cancer Immunol Immunother. 2005;54:383-8.

35. Mehta BA, Schmidt-Wolf IG, Weissman IL, Negrin RS. Two pathways of exocytosis of cytoplasmic granule contents and target cell killing by cytokine-induced CD3 ${ }^{+} \mathrm{CD}_{6}{ }^{+}$killer cells. Blood. 1995;86:3493-9.

36. Liu S, Wang X, Lu Y, Xiao J, Liang J, Zhong X, Chen Y. The combined use of cytokine-induced killer cells and cyclosporine a for the treatment of aplastic anemia in a mouse model. J Interferon Cytokine Res. 2015;35:401-10.
37. Nagy SE, Andersson JP, Andersson UG. Effect of mycophenolate mofetil (RS-61443) on cytokine production: inhibition of superantigen-induced cytokines. Immunopharmacology. 1993;26:11-20.

38. Wang H, Cao F, Li J, Li Y, Liu X, Wang L, Liu Z, Li Y, Zhao H, Zhou J. Homing of cytokine-induced killer cells during the treatment of acute promyelocytic leukemia. Int J Hematol. 2014;100:165-70. 